\title{
Study on the Photocatalytic Oxidation of Gaseous Isopropanol by $\mathrm{Ag} / \mathrm{TiO} 2$
}

\author{
Chih-Ming Ma and Kae-Long Lin
}

\begin{abstract}
Volatile organic compounds are typical gaseous emissions from various industries and pose hazards for human health and environment. Many technologies currently used for the treatment of volatile organic compounds, such as adsorption and scrubbing processes, simply migrates the pollutants from gas phase to another phase. Oxidation is considered to be the most effective way to decompose volatile organic pollutants and various oxidation processes have been studied, developed and implemented for several decades. However, a define need still exists for developing innovative oxidative methods that are prevailingly applicable to most volatile organic compounds. Many researchers have reported the feasibility and reaction mechanisms of titanium dioxide based photocatalytic decomposition of several gas phase organic compounds. However, recombination between electron/hole pairs resulted in low quantum yields for most photocatalytic reactions. In this study, the gaseous Isopropanol were decomposed by UV/Agtitanium dioxide process. In this system, the experimental results indicated that the deposition of $0.04 \% \mathrm{Ag}$ on $\mathrm{TiO}_{2}$ film showed the highest photocatalytic activity among all the composition investigated.
\end{abstract}

Index Terms - Photocatalytic, titanium dioxide, VOC.

\section{INTRODUCTION}

Using photocatalytic oxidation to remove organic contaminants in air has recently received considerable attention since this technology can be potentially applied for air purification in office buildings, factories, homes, cars, and spacecraft. Traditional air purifiers use filters to remove particulate matters or use sorption materials (e.g., granular activated carbon) to adsorb gases or odors. However, these techniques only transfer the contaminants to another phase rather than eliminating them and additional disposal or handling steps are subsequently required. An alternative remediation technology, which offers a number of advantages over conventional technologies, is the use of heterogeneous photocatalytic oxidation. Operating at low or room temperature, the photocatalytic oxidation can degrade a broad range of contaminants into innocuous final products such as $\mathrm{CO}_{2}$ and $\mathrm{H}_{2} \mathrm{O}$ without significant energy input [1].

During the past three decades, more and more researches have focused on the study of reactions on the illuminated semiconductor surface of metal oxides and sulfides consisting mainly of titanium dioxide $\left(\mathrm{TiO}_{2}\right)$, zinc oxide $(\mathrm{ZnO})$, tungsten tri-oxide $\left(\mathrm{WO}_{3}\right)$, and cadmium sulfide $(\mathrm{CdS})$ These materials have a moderate band-gap (1.1-3.7 eV)

Manuscript received October 20, 2016; revised June 12, 2017.

Chih-Ming Ma is with the Department of Cosmetic Application \& Management, Saint Mary's Junior College of Medicine, Nursing and Management, Ilan, Taiwan (e-mail: cmma@smc.edu.tw).

Kae-Long Lin is with the Department of Environmental Engineering, National Ilan University, Ilan, Taiwan (e-mail: kllin@niu.edu.tw). between their valence and conduction bands. When a semiconductor molecule absorbs photons with energy equal to or greater than its band-gap, electrons in the valence band can be excited and jump up into the conduction band and thus charge carriers are generated. When these charge carriers successfully migrate to the solid surface without recombining, the electrons and holes may undergo electron-transfer processes with adsorbates of suitable redox potentials. The photogenerated holes react with the water to produce hydroxyl radicals, while the photogenerated electrons react with molecular oxygen to give superoxide radical anions. These radicals so produced are highly reactive and they work together to completely oxidize the organic species. It is recognized that a hydroxyl radical has a very high thermodynamic oxidation potential, and thus reacts with and mineralizes most organic pollutants by converting them to carbon dioxide and water. Although these are the complex of oxidative reactions, scientific interest in these chemical redox reactions and can be application in environmental protection.

$\mathrm{TiO}_{2}$ is an n-type semiconductor that has three types of crystal structure: anatase, rutile, and brookite. Rutile is the thermodynamically stable form of $\mathrm{TiO}_{2}$, into which anatase and brookite convert when heated above $500^{\circ} \mathrm{C}$ or $750^{\circ} \mathrm{C}$, respectively. Most of the researchers have focused on Degussa $\mathrm{P} 25 \mathrm{TiO}_{2}$ as the photocatalyst. Degussa P25 has an approximate composition of $80 \%$ anatase and $20 \%$ rutile forms of $\mathrm{TiO}_{2}$. It has a BET surface area of about $50 \mathrm{~m} 2 \mathrm{~g}-1$ and a primary particle size of $20 \mathrm{~nm}$. Degussa $\mathrm{P} 25 \mathrm{TiO}_{2}$ is the most used in research because of its well defined nature and substantially high photocatalytic activity as compared to other commercially available options. The photocatalytic reaction occurs in the step 3, upon adsorption of a photon, acts as a catalyst in producing reactive radicals, mainly hydroxyl radicals, which in turn can oxidize organic compounds and totally mineralize them. Thus organic molecules are decomposed to carbon dioxide and water as final products. The basic mechanism of the photocatalytic process has been extensively studied in the literature and several complex reaction pathways have been reported [1], [2].

Efficient and economical removal of a variety of volatile organic compounds (VOC) from air when their concentration is below about 400 ppmv represents a special challenge. Destruction of these pollutants by photocatalytic oxidation is possibly one of the best solutions [3]. Lot of investigations have been conducted in photocatalytic oxidation of gaseous VOCs and several types of photocatalyst systems have been developed [4]-[6]. Lot of organic compounds have been studied in heterogeneous gas-phase photocatalytic oxidation, such as trichloroethylene, tetrachloroethylene, benzene, toluene, xylene, ethanol, ethylene, chloroform, formaldehyde, 
isopropanol, acetone, methyl ethyl ketone. Heterogeneous photocatalytic oxidation has been extensively studied as a promising method for removing toxic organic compounds from air. PCO is cost-effective and can be carried out at room temperature and atmospheric pressure, with good catalyst stability. However, application of PCO in industry has been problematic. Photocatalytic reaction depends on the chemical properties of the pollutants; for example, the conversion of aromatic compounds, such as toluene, is more difficult than that of chlorinated hydrocarbons or alcohols [7]-[9]. Some researchers have reported that the reaction efficiency of BTEX (benzene, toluene, ethylbenzene, and xylenes) depends on the amounts of BTEX adsorbed on the titanium dioxide $\left(\mathrm{TiO}_{2}\right)$ catalyst [10]-[12]. Deactivation of the $\mathrm{TiO}_{2}$ catalyst is also a major disadvantage in the industrial application of PCO. During the PCO of aromatic compounds, less-reactive intermediates are directly responsible for deactivation of the catalyst. These intermediates are strongly adsorbed on the surface of the $\mathrm{TiO}_{2}$ catalyst and deteriorate photoactivity by blocking reaction sites [13]. In this study, the gaseous Isopropanol (IPA) were decomposed by $\mathrm{UV} / \mathrm{TiO}_{2}$ process. The effect of light intensity, effect of initial concentration, effect of humidity, effect of oxygen concentration on the photocatalytic decomposition of gaseous volatile organic compounds were investigated and the apparent quantum efficiencies were calculated.

\section{MATERIALS AND METHODS}

A commercial $\mathrm{TiO}_{2}$ powder catalyst, without pretreatment, was supplied by Degussa (P-25). All chemicals used in the laboratory were of an analytical grade. Half liter of aqueous solution containing $160 \mathrm{~g}$ Degussa P-25 $\mathrm{TiO}_{2}$ particles was held in a $1 \mathrm{~L}$ beaker. $0.02 \mathrm{~g} \mathrm{~L}^{-1}$ dioctyl sulfosuccinate used as dispersing agent was subsequently put into the mixed solution and was stirred by a sonicator for more than 8 hours. A quartz tube or optical fiber was then impregnated in the mixed solution for about one minute before it was took out and air-dried. The coated quartz tube was then put in an oven isothermally at $300{ }^{\circ} \mathrm{C}$ for 2 hours. The Degussa P-25 $\mathrm{TiO}_{2}$ particles were employed as received without further treatment and were approximately spherical and nonporous with greater than $99.5 \%$ purity.

Via the Incipient Wetness Method, Ag was calcined in a modified $\mathrm{TiO}_{2}$ process. First, the critical moisture content of $\mathrm{TiO}_{2}$ was measured by solvent, the fixed amount of metal precursor was dissolved in the de-ionized water with the critical moisture content, $\mathrm{TiO}_{2}$ was slowly added to the metal-containing aqueous solution and well stirred, $\mathrm{TiO}_{2}$ was calcined in a high-temperature furnace, and then the grains pulverized into powder once it had cooled to room temperature. The crystallization level morphology and the specific BET surface area of the photocatalyst was determined by a Siemens D-8 X-ray diffractometer (XRD) and a Micromeritics ASAP 2000 analyzer, respectively.

The photoreactor system employed consisted of a $20 \mathrm{~cm}$ long annular photoreactor that was made exclusively of Pyrex glass with an effective volume of $1.13 \mathrm{~L}$. The photoreactor used consisted of one $1.5 \mathrm{~cm}$ diameter quartz tube housing a GTE F15T8/BLB lamp (365 nm) which was adjusted by a variable voltage transformer. A gas chromatograph equipped with a RTX-624 capillary column and a flame ionization detector was used for the analysis of VOC. An external standard of VOC was injected into gas chromatograph by $0.5 \mathrm{~mL}$ sample loop. Experiments were carried out in the photoreactor. The VOC-laden air stream was prepared by extracting the VOC vapor from the VOC-containing aqueous solution by dewatered compressed air. The initial concentration of VOC and humidity in the air streams was controlled by adjusting the solution temperature. The VOC air stream was flown through the reactor for about 20 minutes until the adsorption of $\mathrm{VOC}$ on $\mathrm{TiO}_{2}$ layer was assumed to reach equilibrium. The UV light source was warmed up for 5 to 10 minutes to achieve a steady light output before it was located on the reactor. At desired time intervals, aliquots of $0.5 \mathrm{ml}$ gaseous sample were withdrawn from the sampling port, which was located at the in and out part of the reactor. Each experimental run in this study was replicated at least twice.

\section{RESULTS AND DISCUSSION}

Peaks marked A and R shown in Fig. 1 indicated the X-ray diffraction patterns of P-25 $\mathrm{TiO}_{2}$ and Ag-deposited $\mathrm{TiO}_{2}$ catalysts corresponding to anatase and rutile phases, respectively. As shown in the curve (b) of Fig. 1 for $0.04 \%$ $\mathrm{Ag} / \mathrm{TiO}_{2}$, the presence of $\mathrm{TiO}_{2}$ in the anatase and rutile forms were detected. However, peaks of $\mathrm{Ag}_{2} \mathrm{O}$ found in the curves (c) and (d) indicate that increasing the $\mathrm{Ag}$ amount deposited on $\mathrm{TiO}_{2}$ enhanced the peak intensity of $\mathrm{Ag}_{2} \mathrm{O}$. The surface area of $\mathrm{Ag} / \mathrm{TiO}_{2}$ from the Brunauer-Emmett-Teller surface area measurements (B.E.T.) were only slightly increased as shown in Table I. On the basis of the XRD results (Table I), the crystal sizes (D) of $\mathrm{Ag} / \mathrm{TiO}_{2}$ powder can also be estimated using the Scherrer equation:

$$
D=\frac{K \lambda}{B \cos \theta}
$$

where $\mathrm{D}$ is the crystal size, $\lambda$ is the $\mathrm{X}$-ray wavelength corresponding to $\mathrm{Cu} \mathrm{K} \alpha$ radiation, $\theta$ is the diffraction angle, and $\mathrm{B}$ is full width half maximum of diffraction peak at $2 \theta$. K is the Scherrer constant as 0.90 . The crystal sizes (D) of all samples indicate that the anatase crystal size slightly decreased from 19.2 to $15.8 \mathrm{~nm}$ and the rutile crystal size slightly decreased from 28.6 to $26.2 \mathrm{~nm}$. The photoactivity of Ag coated $\mathrm{TiO}_{2}$ surface was apparently affected via the covalently anchored property such as of lattice parameters and the unit cell volume of $\mathrm{Ag} / \mathrm{TiO}_{2}$.

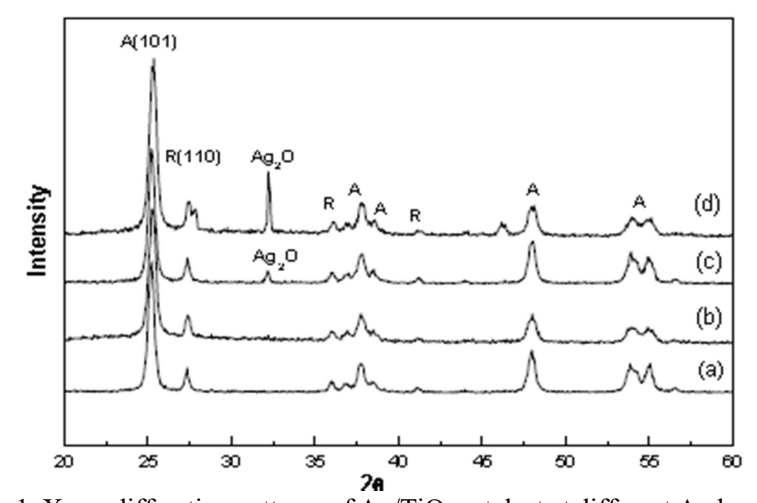

Fig. 1. X-ray diffraction patterns of $\mathrm{Ag} / \mathrm{TiO}_{2}$ catalyst at different $\mathrm{Ag}$ loadings: (a) $\mathrm{TiO}_{2}(\mathrm{P} 25)$ (b) $0.04 \% \mathrm{Ag} / \mathrm{TiO}_{2}$ (c) $0.5 \% \mathrm{Ag} / \mathrm{TiO}_{2}$ (d) $1.0 \% \mathrm{Ag} / \mathrm{TiO}_{2}$. 
TABLE I: SURFACE AREA AND CRYSTAL SIZE OF $\mathrm{TIO}_{2}(\mathrm{P} 25)$ AND AG DEPOSITED ON $\mathrm{TIO}_{2}$

\begin{tabular}{lllll}
\multicolumn{5}{c}{ DEPOSITED ON $\mathrm{TIO}_{2}$} \\
\hline Materials & $\begin{array}{l}\text { Actual } \\
\text { loading of } \\
\mathrm{Ag}(\text { wt.\%) }\end{array}$ & $\begin{array}{l}\text { Crystal size } \\
\text { of anatase } \\
(\mathrm{nm})\end{array}$ & $\begin{array}{l}\text { Crystal size of } \\
\text { rutile }(\mathrm{nm})\end{array}$ & $\begin{array}{l}\text { Surface } \\
\text { area } \\
\left(\mathrm{m}^{2} \mathrm{~g}^{-1}\right)\end{array}$ \\
\hline $\mathrm{TiO}_{2}$ & 0 & 19.2 & 28.6 & 53.61 \\
$0.04 \% \mathrm{Ag} / \mathrm{TiO}_{2}$ & 0.04 & 16.8 & 26.3 & 53.80 \\
$0.50 \% \mathrm{Ag} / \mathrm{TiO}_{2}$ & 0.47 & 16.3 & 26.1 & 53.86 \\
$1.00 \% \mathrm{Ag} / \mathrm{TiO}_{2}$ & 0.95 & 15.8 & 26.2 & 57.82 \\
\hline
\end{tabular}

${ }^{*} \mathrm{Ag}$ loading was determined by AA.

The photodecomposition of gaseous IPA by $\mathrm{UV} / \mathrm{TiO}_{2}$ process for experiments conducted in the annular photoreactors coated with various catalysts under various inlet IPA concentrations between 140 and 520 ppmv at a residence time of 169.5 seconds, light intensity of $3.09 \mathrm{~mW}$ $\mathrm{cm}^{-2}$, gas flow rate of $400 \mathrm{~mL} \mathrm{~min}^{-1}$, relative humidity $10 \%$ are presented in Fig. 2(a) and Fig. 2(b). The decomposition efficiencies of IPA in reactor coated with P-25 TiO2 decreased from $71 \%$ (for experiments conducted at $140 \mathrm{ppmv}$ IPA) to $48 \%$ (for experiments conducted at 520 ppmv IPA), $0.04 \% \mathrm{Ag} / \mathrm{TiO}_{2}$ decreased from $92 \%$ (for experiments conducted at $140 \mathrm{ppmv}$ IPA) to $78 \%$ (for experiments conducted at 520 ppmv IPA), $0.5 \% \mathrm{Ag} / \mathrm{TiO}_{2}$ decreased from $91 \%$ (for experiments conducted at 140ppmv IPA) to $77 \%$ (for experiments conducted at 520 ppmv IPA), $1 \% \mathrm{Ag} / \mathrm{TiO}_{2}$ decreased from $87 \%$ (for experiments conducted at $140 \mathrm{ppmv}$ IPA) to $71 \%$ (for experiments conducted at $520 \mathrm{ppmv}$ IPA). The $\mathrm{CO}_{2}$ generation ratio decreased from 56 to $21 \%(\mathrm{P}-25$ $\left.\mathrm{TiO}_{2}\right), \quad 89$ to $68 \% \quad\left(0.04 \% \mathrm{Ag} / \mathrm{TiO}_{2}\right), \quad 89$ to $67 \%$ $\left(0.5 \% \mathrm{Ag} / \mathrm{TiO}_{2}\right)$, and 81 to $61 \%\left(1 \% \mathrm{Ag} / \mathrm{TiO}_{2}\right)$.

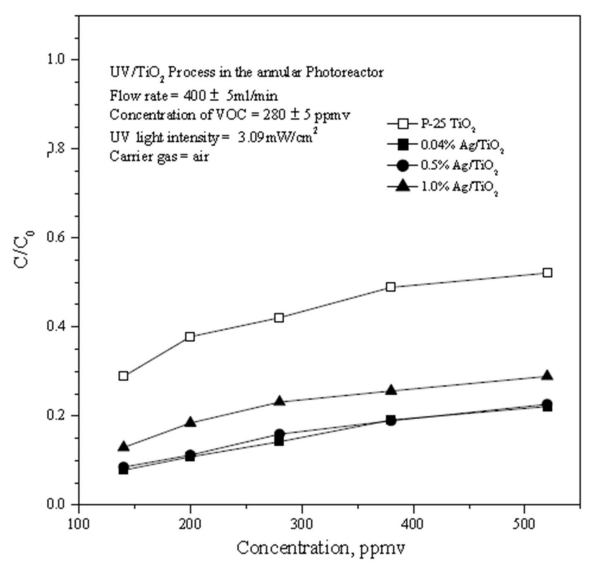

(a)

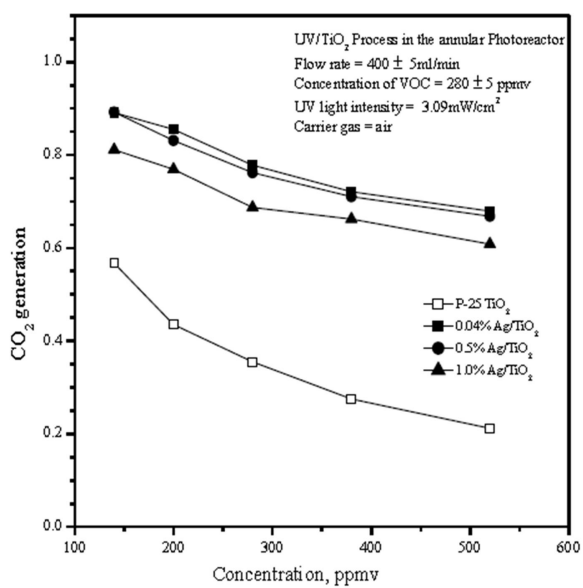

(b)

Fig. 2. Effect of initial concentration on the IPA decomposition and the $\mathrm{CO}_{2}$ generation ratio by photocatalytic oxidation at various photocatalysts $(\mathrm{P}-25$ $\mathrm{TiO}_{2}, \mathrm{Ag} / \mathrm{TiO}_{2}$ ) in the annular photoreactor
Fig. 3(a) and 3(b) depict the effect of light intensity on the IPA decomposition and $\mathrm{CO}_{2}$ generation by $\mathrm{UV} / \mathrm{TiO} 2$ process coated with various catalysts. The decomposition rates of IPA were increased almost linearly with light intensity in the range of 1.43 to $4.08 \mathrm{~mW} \mathrm{~cm}^{-2}$ with $\mathrm{P}-25 \mathrm{TiO}^{2}$ increased from $36 \%$ (for experiments conducted at $1.43 \mathrm{~mW} \mathrm{~cm}^{-2}$ ) to $60 \%$ (for experiments conducted at $4.08 \mathrm{~mW} \mathrm{~cm}^{-2}$ ), $61 \%$ to $90 \%\left(0.04 \% \mathrm{Ag} / \mathrm{TiO}_{2}\right), 58$ to $89 \%\left(0.5 \% \mathrm{Ag} / \mathrm{TiO}_{2}\right)$, and 54 to $87 \%\left(1 \% \mathrm{Ag} / \mathrm{TiO}_{2}\right)$. But for light intensity higher than 3.09 $\mathrm{mW} \mathrm{cm}{ }^{-2}$, the effect of light intensity on the decomposition rate of IPA was retarded with various catalysts loadings.

Furthermore, the $\mathrm{CO}_{2}$ generation increased from 18 to $42 \%$ $\left(\mathrm{P}-25 \mathrm{TiO}_{2}\right), 44$ to $81 \%\left(0.04 \% \mathrm{Ag} / \mathrm{TiO}_{2}\right), 41$ to $81 \%$ $\left(0.5 \% \mathrm{Ag} / \mathrm{TiO}_{2}\right)$, and 39 to $79 \%\left(1 \% \mathrm{Ag} / \mathrm{TiO}_{2}\right)$. Fig. 2 to Fig. 3 show that the photocatalytic performance of $\mathrm{TiO}_{2}$ films could be improved by the addition of $\mathrm{Ag}$ and the decomposition rates are larger than $\mathrm{TiO}_{2}$ only films. In this system, the experimental results indicated that the deposition of $0.04 \%$ $\mathrm{Ag}$ on $\mathrm{TiO}_{2}$ film showed the highest photocatalytic activity among all the composition investigated. The decomposition rate and $\mathrm{CO}_{2}$ generation are $0.04 \% \quad \mathrm{Ag} / \mathrm{TiO}_{2}>0.5 \%$ $\mathrm{Ag} / \mathrm{TiO}_{2}>1 \% \mathrm{Ag} / \mathrm{TiO}_{2}>$ pure $\mathrm{TiO}_{2}$.

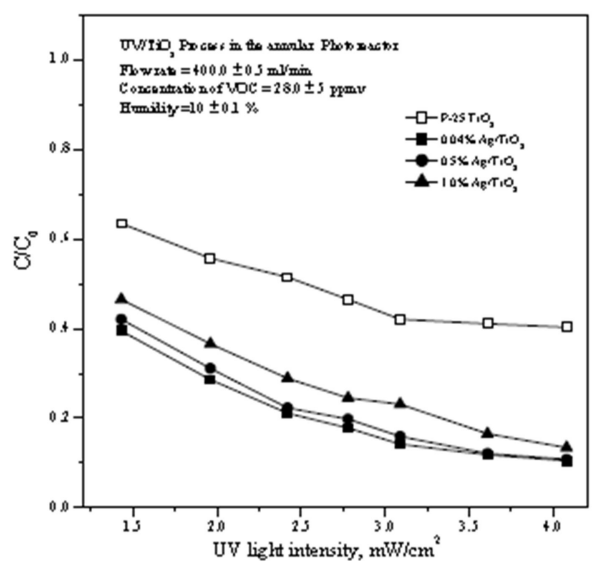

(a)

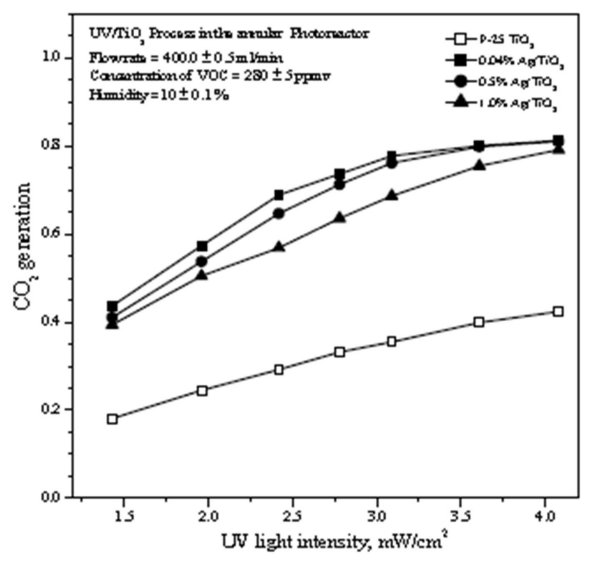

(b)

Fig. 3. Effect of UV light intensity on the IPA decomposition and the $\mathrm{CO}_{2}$ generation ratio by photocatalytic oxidation at various photocatalysts (P-25 $\mathrm{TiO}_{2}, \mathrm{Ag} / \mathrm{TiO}_{2}$ ) in the annular photoreactor.

The rate equation was solved and summarized in Table II. The major role of silver or silver oxide incorporated on $\mathrm{TiO}_{2}$ could be treated as a scavenger in conduction band to decrease the probability of recombination of electrons and holes. However, silver or silver oxide coating usually causes 
some new problems to result in the decreased photocatalytic activity of $\mathrm{TiO}_{2}$ such as competition occupancy of silver or silver oxide deposits on $\mathrm{TiO}_{2}$ surface to reduce its activity. Another problem is that silver or silver oxide on the $\mathrm{TiO}_{2}$ surface are large enough to become new recombination centers of electrons and holes due to the decrease of electron transfer rate to the oxidant. The order of UV light intensity, adsorption equilibrium constant (Table II) helps to define the reasons. The comparison of the order of UV light intensity shows that $1 \% \mathrm{Ag} / \mathrm{TiO}_{2}$ is slightly more than $0.5 \% \mathrm{Ag} / \mathrm{TiO}_{2}$. In addition, it is very clear that the adsorption equilibrium constant of IPA on photocatalyst is pure P-25 $\mathrm{TiO}_{2}$ $>0.04 \% \mathrm{Ag} / \mathrm{TiO}_{2}>0.5 \% \mathrm{Ag} / \mathrm{TiO}_{2}>1 \% \mathrm{Ag} / \mathrm{TiO}_{2}$. It can be explained that $\mathrm{Ag}$ may cover and occupy of some semiconductor surfaces, causing the decrease the adsorption equilibrium constant, and photocatalytic ability as well.

TABLE II: REACTION RATE CONSTANT OF DECOMPOSITION OF IPA ADSORPTION EQUILIBRIUM CONSTANT OF IPA, AND THE ORDER OF UV LIGHT INTENSITY ARE DETERMINED UNDER VARIOUS PHOTOCATALYSTS

\begin{tabular}{lclc}
\multicolumn{4}{c}{ (P-25 TIO2, AG/TIO2) IN THE ANNULAR PHOTOREACTOR } \\
\hline Materials & $k\left(\mathrm{ppmv}^{-1} \mathrm{~cm}^{-2} \mathrm{sec}^{-1}\right)$ & $K\left(\mathrm{ppmv}^{-1}\right)$ & $n$ \\
\hline $\mathrm{TiO}_{2}$ & 0.9595 & 0.00456 & 0.6207 \\
$0.04 \% \mathrm{Ag} / \mathrm{TiO}_{2}$ & 1.8078 & 0.00440 & 0.6808 \\
$0.50 \% \mathrm{Ag} / \mathrm{TiO}_{2}$ & 1.7272 & 0.00410 & 0.7361 \\
$1.00 \% \mathrm{Ag} / \mathrm{TiO}_{2}$ & 1.5716 & 0.00386 & 0.7445 \\
\hline
\end{tabular}

\section{CONCLUSION}

In this study, the results obtained had been shown to be feasible for decomposing gaseous IPA in air streams. It was found that increasing the inlet IPA concentrations decreased the decomposition and the mineralization rates of IPA. It was indicated that excessive dosages of IPA in air stream decrease the decomposition rate owing to the limited amount of active sites on the surface of $\mathrm{TiO}_{2}$, which was available for the adsorption and reaction of reactants. Light intensity was also an important parameter that influenced the decomposition of pollutants by photocatalytic processes. An increase of light intensity may increase the number of photons striking on the surface of photocatalyst to form more electrons and holes. Furthermore, the mineralization rate of IPA was increased while enhancing the UV light intensity. In this system, the experimental results indicated that the deposition of $0.04 \% \mathrm{Ag}$ on $\mathrm{TiO}_{2}$ film shows the highest photocatalytic activity among all the composition investigated. The decomposition rate and $\mathrm{CO}_{2}$ generation were $0.04 \% \mathrm{Ag} / \mathrm{TiO}_{2}>0.5 \% \mathrm{Ag} / \mathrm{TiO} 2>1 \% \mathrm{Ag} / \mathrm{TiO}{ }_{2}>$ pure $\mathrm{TiO}_{2}$. The major role of silver or silver oxide incorporated on $\mathrm{TiO}_{2}$ could be treated as a scavenger in conduction band to decrease the probability of recombination of electrons and holes.

\section{ACKNOWLEDGMENT}

The authors would like to thank the Ministry of Science and Technology (Republic of China, TAIWAN), for financially supporting this research under Contract No. NSC 101-2221-E-562-003-MY3.

\section{REFERENCES}

[1] S. B. Kim and S. C. Hong, "Kinetic study for photocatalytic degradation of volatile organic compounds in air using thin film $\mathrm{Tio}_{2}$ photocatalyst," Appl. Catal. B: Environ., vol. 35, no. 2, pp. 305-315, 2002.

[2] P. Avila, A. Bahamonde, J. Blanco, B. Sanchez, A. I. Cardona, and M. Romero, "Gas-phase photo-assisted mineralization of volatile organic compounds by monolithic titania catalysts," Appl. Cata. B. Environmental, vol. 17, no. 1-2, pp. 75-88, 1998.

[3] L. Wang, M. Sakurai, and H. Kameyama, "Study of catalytic decomposition of formaldehyde on $\mathrm{Pt} / \mathrm{TiO}_{2}$ alumite catalyst at ambient temperature," Journal of Hazardous Materials, vol. 167, pp. 399-405. 2009.

[4] M. Hussain, N. Russo, and G. Saracco, "Photocatalytic abatement of VOCs by novel optimized TiO2 nanoparticles," Chem. Eng. J, vol. 166, pp. 138-149, 2011

[5] S. Lorencik, Q. L. Yu, and H. J. H. Brouwers, "Photocatalytic coating for indoor air purification: Synergetic effect of photocatalyst dosage and silica modification," Chem. Eng. J, vol. 306, pp. 942-952, 2016.

[6] R. Molinari, C. Lavorato, and P. Argurio, "Photocatalytic reduction of acetophenone in membrane reactors under UV and visible light using $\mathrm{TiO}_{2}$ and $\mathrm{Pd} / \mathrm{TiO}_{2}$," Chem. Eng. J, vol. 274, pp. 307-316, 2015.

[7] O. d'Hennezel, P. Pichat, and D. F. Ollis, "Benzene and toluene gas-phase photocatalytic degradation over $\mathrm{H}_{2} \mathrm{O}$ and hcl pretreated $\mathrm{TIO}_{2}$ : by-products and mechanisms," J. Photochem. Photobio. A: Chemistry, vol. 118, pp. 197-204, 1998.

[8] F. C. Marques, M. C. Canela, A. M. Stumbo, "Use of Tio $2 / \mathrm{cr}-\mathrm{mcm}-41$ molecular sieve irradiated with visible,"Catal. Today, vol. 133-135, pp. 594-599, 2008.

[9] T. T. Y. Tan, C. K. Yip, D. Beydoun, and R. Amal, "Effects of nano-ag particles loading on $\mathrm{tio}_{2}$ photocatalytic reduction of selenate ions," Chem. Eng. J., vol. 95, pp. 179-186, 2003.

[10] M. A. Fox and M. T. Dulay, "Heterogeneous photocatalysis," Chem. Rev., vol. 93, no. 1, pp. 341-357, 1993.

[11] J. Jeong, K. Sekiguchi, and K. Sakamoto, "Photochemical and photocatalytic degradation of gaseous toluene using short-wavelength uv irradiation with $\mathrm{Tio}_{2}$ catalyst: comparison of three uv sources," Chemosphere., vol. 51, pp. 663-671, 2008.

[12] Q. Dai, X. Wang, and G. Lu, "Low-temperature catalytic combustion of trichloroethylene over cerium oxide and catalyst deactivation," Applied Catalysis., vol. 81, pp. 192-202, 2008.

[13] J. S. Jang, H. G. Kim, S. M. Ji, S. W. Bae, J. H. Jung, B. H. Shon, and J. S. Lee, "Formation of crystalline $\mathrm{TiO}_{2} \mathrm{xNx}$ and its photocatalytic activity," J. Solid State Chem., vol. 179, pp. 1067-1075, 2006.

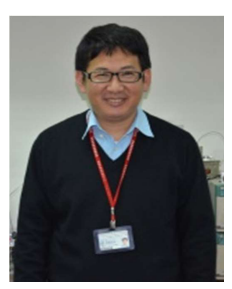

Chih-Ming Ma is a professor in the Department of Cosmetic Application \& Management, Saint Mary's Junior College of Medicine, Nursing and Management, Ilan, Taiwan, Republic of China.

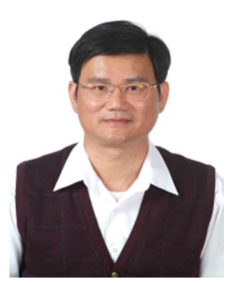

Kae-Long Lin is a professor in Department of Environmental Engineering National Ilan University, Taiwan, 26047, Republic of China. 